\title{
SCHILLING, F. (2014). A SOCIEDADE DA INSEGURANÇA E A VIOLÊNCIA NA ESCOLA. SÃO PAULO: SUMMUS.
}

DOI: $10.22289 / 2446-922 X . V 8 N 1 A 4$

Lucas Carolino ${ }^{1}$

O livro A sociedade da insegurança e a violência na escola de autoria de Flávia Schilling, fala de um sentimento de insegurança característico da sociedade contemporânea, sua influência nas escolas e no desencadeamento da violência. Ela aborda que: "não há como separar o que se vive no mundo maior do que se vive na escola" (Schilling, 2014, p.92). Esta é a tese do livro.

Podemos dizer que algumas questões invisíveis até certo tempo na sociedade começam a se tornar visíveis, como dimensões da violência: coletiva, individual, estrutural. Nessa perspectiva um avanço que pode estar em curso é a desnaturalização da violência por meio da sua visibilidade.

Assim, o objetivo do manuscrito é apresentar para o leitor subsídios para compreender as dimensões da violência e possibilidades de intervenções que visam a sua desnaturalização e minimização dos seus impactos.

Na parte inicial do livro (apresentação) a autora promete centrar os assuntos analisando o Brasil e na violência em três níveis "na" escola, "da" escola, e "contra" a escola (Schilling, 2014, p.13). Ainda, apresenta as dimensões da violência que serão tratadas no livro: história, geografia, matemática e gramática, neste tópico, relata que apresentará saídas possíveis (que serão abordadas neste texto na descrição do quarto capítulo).

O livro é dividido em quatro eixos, ou seja, quatro capítulos. No primeiro capítulo a autora apresenta os parâmetros gerais da sociedade da insegurança, isto é, o contexto: a sociedade da insegurança. Logo, no início, a autora manifesta que a temática abordada ainda não foi superada e expõe que o assunto ainda está presente na atualidade, principalmente, no Brasil, nos cotidianos das escolas, nos discursos e na mídia.

É recorrido a Bauman para refletir o contexto da insegurança na contemporaneidade. Ele se torna o autor central para pensarmos a nossa incerteza, a quebra de garantias que possivelmente "tínhamos" e que como consequência trouxe a insegurança para o nosso tempo. O autor Bauman nos convida a pensar em três conceitos (segurança, certeza e garantias) que nos trariam "autoconfiança" nos dias atuais.

\footnotetext{
${ }^{1}$ Endereço eletrônico de contato: lucascarolino851@gmail.com

Recebido em 06/10/2021. Aprovado pelo conselho editorial para publicação em 04/01/2022.
}

Rev. Psicol Saúde e Debate. Jan., 2022:8(1): 47-59. 
Lendo estes pontos, apontados por Bauman, Schilling (2014) retrata a parte que nos inquieta, que não se sabe se o que conquistamos nos trará garantias e certezas como: o emprego conquistado, a casa, se o diploma trará garantias juntamente com todo o estudo empenhado, inclusive, os valores até aqui possivelmente construídos como a honestidade. Em comentário Schilling (2014, p. 19) relata: "estamos cercados de "medos ambiente", sem saber se nosso planeta, nosso mundo, nossa vizinhança escaparão dos perigos".

Ainda, neste capítulo é apresentado a matemática da violência, entre as páginas 19 e 20 evidenciando dados do desemprego que também é um tipo de violência, assim, apresenta-se dados do IBGE de 1992 e 2002 que demonstra um aumento do desemprego de 40\% nesse período e, passando para a verificação dos anos de 2002 a 2014, na comparação com 2003 e com 2013 na taxa de desocupação foi possível analisar que a mesma havia caído 49,5\% na comparação com 2003.

Apesar disso, a autora apresenta na página 20 que na quebra de certezas e garantias, um dos fatores que gera insegurança na atualidade são as transformações das situações de trabalho geradas pelo capitalismo, que é "volátil" e "fluido", "instantâneo", (Schilling, 2014). Referindo-se ao conceito de Bauman de "'flexibilidade", Schilling (2014) expõe que surge neste cenário o dogma da "flexibilidade", onde não é gerado espaço para a "igualdade" e homogeneidade de posições, portanto, é pregado discursivamente que é preciso ser flexível. A autora destaca ainda que:

Em tempos de "globalização", "mundialização", "sociedade pós-industrial", "pós-modernidade", "modernidade radical", não se supõe a existência de uma igualdade de acesso aos novos bens ou às novas possibilidades. Isso não quer dizer que estamos condenados à incerteza, que assistiremos passivos à nossa derrocada. Há possibilidades, sim, constantemente postas. Existem formas de inserção na ordem mundial que não implicam relações extremas de dependência. Há, sempre, uma margem que possibilita novas configurações, há um "não" possível a ser dito - se não total, ao menos parcial (Schilling, 2014, p.21).

Além disso, nos modelos de produção capitalista o que gera desigualdade social pode ser os incentivos fiscais para empresas moverem suas fábricas por estes incentivos e devido também a mão de obra barata por meio da "fixação" da homogeneidade dos trabalhadores. Este aspecto limita a capacidade de luta dos trabalhadores, pois é feito também uma quebra de instituições que constituíam medidas coletivas que mantinham certa certeza dos trabalhadores em seus limites por meio de representação e ações.

Baseando-se no pensamento de Bauman da quebra de certezas e de representações dos trabalhadores produzidas, Schilling (2014) faz uma análise, uma espécie de diagnóstico social do Brasil e do nosso contexto, diz que as instituições que limitavam o grau de incerteza dos trabalhadores Ihe davam mais segurança, eram instituições relacionadas as garantias da 
previdência social e dos direitos trabalhistas que foram arduamente conquistados por lutas dos séculos 19 e 20.

No Brasil após 1988 com a Constituição Federal há tentativas de fortalecer essas instituições para garantir os direitos sociais. Schilling (2014, p.23) aponta que quando se muda essa situação dos direitos sociais conquistados nos séculos 19 e 20 "há um evidente impacto, em todos nós, dessa precarização da existência, e o mesmo se dá quando se inverte essa situação".

No século XVIII Bauman aponta que na sociedade da incerteza (insegurança), buscou-se na cultura explicações para se ter segurança e para três questões fundamentais (De onde venho? O que devo fazer da vida? O que acontece após a morte? Ou seja, procurou-se certeza na cultura para suspender a insegurança da morte (finitude).

Além disso, a autora fundamentando-se em Bauman fala que buscamos saídas da finitude em outras explicações como: "religiosas, da nacionalidade, da família e da classe social" (Schilling, 2014, p.24). A página 24 é central para o leitor obter reflexões e fundamentos sobre a sociedade da insegurança. No parágrafo $3^{\circ}$ a autora relata: "como aparentemente não é possível atacar as causas estruturais que geram a incerteza, a insegurança e a quebra de garantias, vemos a criminalização de comportamentos" (Schilling, 2014, p.24).

Assim, estes comportamentos aparecem como uma quebra da segurança e não da ordem como era caracterizado no período anterior. O sentimento da insegurança segundo Bauman aconteceu devido mudanças estruturais que ocorreram derivadas dos âmbitos macroeconômico e o político, e assim, tiraram nossos direitos sociais. Buscar controlar o sentimento de insegurança advindo dessas questões estruturais é difícil, somente haveria esta possibilidade pensando no nível de novas mudanças estruturais que viriam da nossa participação na política e na busca de sua reinvenção. Segundo Bauman tentamos controlar esse sentimento de insegurança na busca da segurança privada e, portanto, essa lógica nos trouxe mais insegurança e afastamento da participação da política.

Buscar segurança incessantemente somente aumenta o nosso medo. Transferir o medo e buscar a ordem por meio da segurança, somente aumenta a sensação de medo. Em dados de 2004 é confirmado essa conjectura no livro na página 30 pela Folha de São Paulo e pelo Departamento Penitenciário Nacional (DEPEN) que indicava que São Paulo era o estado com maior número de presos 99.026. Em 2012 em nova pesquisa, em atualização de dados, São Paulo permaneceu como o estado com maior número de presos 163.915.

Em estudos de Bauman é retratado que quando a sociedade busca por segurança e não por espaços coletivos, públicos e políticos para construções coletivas e buscas de opções para lidar com a violência, inclusive, para escola. Temos como consequência que: "quando não mais sabemos formular projetos comuns que nos orientem para a vida coletiva, construímos mais prisões". (Schilling, 2014, p.30).

Rev. Psicol Saúde e Debate. Jan., 2022:8(1): 47-59. 
Outra saída que buscamos para Bauman é refugiar-se nas nossas comunidades com os "iguais", ou seja, nas identidades "semelhantes" e, assim, nos fechamos nas comunidades. Isso também acontece devido à dificuldade/impossibilidade de termos um projeto de vida que seja comum. Isso: A) aumenta as incertezas. B) nos faz buscar a certeza da segurança do corpo e dos bens.

Nessa situação, por meio de conhecimentos fundamentados em Bauman, Schilling (2014) salienta que se diminui a nossa participação coletiva na busca de projetos de vida comum e o que acontece é que os tidos como detentores dos espaços (representantes dos espaços públicos) continuarão a nos prometer espaços públicos sem medos.

Vê-se uma necessidade de que pensemos de forma coletiva sobre o que seria a sociedade justa e quais seriam os modelos do bem, da boa vida, que nos permitiriam definir os bens comuns, os bens públicos a serem preservados e defendidos (Schilling, 2014). Essa é a proposta do livro para reflexões na escola. Para pensarmos outros significados de violência, segurança, esperança, vida, liberdade e entre outros assuntos. Porém são propostas para pensar, refletir, agir e não buscar certezas e seguranças de forma individual, como apontado, isso aumenta o sentimento de medo e nos distancia do espaço público.

Ao final deste capítulo, podemos retratar nossa tarefa enquanto sociedade: buscar o bem comum coletivo, essa é a nossa tarefa na sociedade da insegurança, os caminhos individuais, nesse sentido, não são garantias para viver juntos com justiça e uma vida digna. Bauman sugere reinventar a política, participar do público por meio dela de modo democrático, impondo nos também os limites individuais e coletivos.

Vida digna, nesse sentido, a autora propõe reflexões baseadas nos direitos sociais para além do artigo 3ํ da Declaração dos Direitos Humanos da Organização das Nações Unidas (ONU). Resumindo, o capítulo primeiro apresenta o contexto atual que nos gera insegurança de modo coletivo, este aparenta ser individual, por isso, buscamos individualmente segurança por: A) segurança no direito penal. B) investimento na estética no corpo para ingressar no trabalho. C) Investimento no consumo.

O segundo capítulo apresenta "A violência na sociedade da insegurança", descreve sobre um debate em curso sobre a "linguagem da violência", sua gramática é falada por um lugar discursivo de saber "predominantemente jurídico/médico, epidemiológico/militar? As perguntas seriam: quem pode falar, contra quem, a favor de quem, de que maneira?" (Schilling, 2014, p.39). Nessa gramática de linguagem, as vítimas quase "sempre" são faladas por outros, silenciadas, pelas relações sociais existentes. A autora fala que a violência é multidimensional, com isso, a pergunta inicial que deveríamos fazer é "a que tipo de violência nos referimos quando falamos em violência?" (Schilling, 2014, p.40). 
Há quatro tipos de violência apresentadas, violência física, psicológica, emocional e simbólica, e essas, agem de formas diferentes em dimensões macro e micro em seus contextos e também de formas relacionadas e merecem ações diferentes. Em relação as vítimas das violências e seus sofrimentos psíquicos, a autora apresenta uma insuficiência de alguns trabalhos:

Insuficientes, inclusive, por não considerarem que, além da vítima direta, há vítimas indiretas nessas situações. Não contamos, no entanto, com trabalhos sobre a problemática da criança, do jovem e do adulto em contato direto com a morte violenta e com a violência característica da criminalidade urbana, com a vitimização direta ou indireta por ela produzida (Schilling, 2014, p.41).

A autora observa que há uma necessidade de buscar intervenções com os agressores e ouvi-los. Caso contrário, há um duplo silenciamento (vítimas diretas/indiretas) e como consequência os agressores serão sempre discursivamente falados por especialistas. Neste silenciamento, as vítimas (no caso nós) não seremos os mesmos após construções de "subjetividades atemorizadas", pela mídia.

A autora apresenta que há múltiplas violências, isso aponta para a sua multidimensionalidade/complexidade e para uma quebra importante e necessária para aqueles que tentam simplificar o seu contexto, simplificação que produz silenciamento e sofrimento por meio da fala, apenas, dos especialistas.

Nas definições possíveis de violência, a autora fala da violência social conceituada por Michaud em 1989 no trabalho "A violência", que esta deve ser compreendida para além dos danos físicos, ou seja, sua compreensão se dá por meio dos danos morais e materiais (posses) que afetam uma ou mais vítimas.

Ainda, aponta a concepção da violência social que a autora descreve que ela é estrutural na sociedade e trata os seres humanos como coisas e são, portanto, dimensões da violência relacionadas com as violações de direitos humanos. Schilling comenta que por meio desta violência é possível falar de desemprego e suas ameaças, fome, miséria e também exclusão.

Ao analisar a violência por uma perspectiva histórica de Marilena Chaui, Schilling traz reflexões e comenta sobre a colonização do nosso país:

Questiona-se a visão histórica que relata um encontro feliz entre raças, com uma colonização benigna, que nos diz que vivemos em um país sem guerras ou revoluções sangrentas, sem tufões, ciclones, terremotos, "bonito por natureza". Os direitos, mais do que conquistados, teriam sido dádivas de governantes benevolentes. A independência, a República, a Abolição da escravatura, a conquista dos direitos sociais torna-se, nessa visão, fruto da atuação de alguns homens visionários. Aparentemente foram "concedidos". Ficam guardadas - nos porões da memória coletiva - as lutas (Schilling, 2014, p.44-45).

Rev. Psicol Saúde e Debate. Jan., 2022:8(1): 47-59. 
Nesse ponto de vista a violência tem sua história, bem como sua (s) continuidade (s) e rupturas, assim, como a violência contra a mulher (doméstica) que por muito tempo foi algo visto como um disciplinamento, semelhante como é visto com as crianças em fase de "adaptação" aos disciplinamentos (regras da sociedade), conforme é abordado no livro.

A autora trata, ainda, da violência do ponto de vista da epidemia (médico e social) que busca uma separação do doente/sadio e uma organização da sociedade de acordo com este ponto de vista metafórico.

Na relação da violência com a criminalidade, é visto que o sentimento de medo/insegurança e desesperança da política (ausência de participação dos espaços públicos) é um dos problemas que afetam a construção da democracia. Como consequência advinda da corrupção nos afastamos da gestão pública e da política. É sintetizado que há uma relação muito profunda com a violência e poder econômico, pois a violência gera lucros do ponto de vista econômico (empregos / movimenta indústrias). Nessa análise a autora examina a relação estrutural da sociedade com este sistema econômico.

Esse sistema estrutural/econômico movimenta: 1- trabalho, 2-consumo, 3- crime. Estruturalmente aumenta o índice de presidiários e a autora descreve em estudo dos anos 2013 e 2014 um aumento da população carcerária mundial e do Brasil, inclusive, ocupando um dos quatro países com maior população carcerária do mundo e dentre os outros três (Estados Unidos, China e Rússia) era o único país que estava operando fora de sua capacidade prisional.

No quesito estrutural a autora analisa o Mapa da Violência (2013), as mortes violentas de homicídio, acidentes de transporte, suicídio e, posteriormente, o leitor pode encontrar a geografia desta violência na página 55. Entre as páginas 55-57 a autora observa a mudança de paradigma entre a Fundação Estadual do Bem-Estar do Menor (FEBEM) para o Centro de Atendimento Socioeducativo do Adolescente (Fundação Casa) e diz que devido a criação de novos centros socioeducativos e mudanças legislativas e de atendimento (descentralizado), apresentou-se diminuição das reincidências de crimes e rebeliões.

O livro fornece caminhos para o leitor aprofundar conhecimentos de outros autores como Bauman e Arendt, através destes, poderá entender profundamente a sociedade da insegurança e sobre o que é a violência e o que é o poder.

A autora coloca em pauta que a busca da construção de uma gestão democrática (gestão/governo) na escola é uma das formas de lidar com as violências. Outra proposta seria o entendimento de que violência e poder não se coincidem e até mesmo são conceitos opostos, conforme é citado no livro por intermédio de Arendt, Schilling (2014) retrata que o poder é diferente da violência, pois no poder as ações são realizadas por acordo e propõe limites das ações permitidas de formas coletivas e individuais. Já a violência onde ela está o poder está ausente, pois não há busca de diálogos e acordos. 
O terceiro capítulo A violência nas/das escolas: a escola é o céu ou o inferno? A autora busca realizar um debate sobre as violências na escola e a indagação sobre qual seria sua função (papel) na contemporaneidade? Na perspectiva histórica são apontados alguns papéis desempenhados pela escola: de reprodução das desigualdades sociais, de gênero, raça por meio da colonização da educação. Busca-se em Durkheim refletir do ponto de vista histórico sobre o papel da educação na sociedade, que seria a divisão (reprodução) social do trabalho. No Brasil, fica evidente essa questão, a partir, dos anos 1960 quando a escola também se afasta da construção democrática.

A autora neste capítulo reflete que: A educação cria homens médios, plásticos, e heterogêneos para uso de proveito do trabalho nas funções da sociedade. Na sociedade isto é tido como normal, isto é, a educação para a divisão do trabalho, assim, por meio da diversidade e das aptidões naturais, há a reprodução do seu lugar no trabalho por intermédio da educação e também da proposta da flexibilidade da divisão do trabalho.

Ainda, é proposta uma reflexão: "Que com o auxílio da psicologia, da sociologia e da história, introduziria nesses homens (crianças) eminentemente plásticos, pela força da persuasão, o espírito da disciplina, da abnegação e da autonomia para a perpetuação da sociedade" (Schilling, 2014, p.67).

A autora propõe que educação em direitos humanos e sua prática nas escolas pode possibilitar o uso da liberdade, garantias de direitos sociais e bem como os econômicos, visto os artigos II, XXV, XXVI e XXVII da Declaração Universal dos Direitos Humanos de 1948 e seus parâmetros universais. Escolas que se afastam dessas propostas é posto que mais que parecem prisões e, por isso, chamam-se por mais policiais e segurança.

Algumas escolas buscam por mais segurança e outras fazem o contrário, assim, refletem questões de violências. "Bloqueiam o medo, incentivam a participação, abrem-se às vizinhanças, descriminalizam condutas e acolhem as pessoas" (Schilling, 2014, p.73). Deste modo, é colocado neste capítulo que a escola e a educação como um direito pode ser pensada/realizada.

A autora apresenta duas pesquisas nas páginas 77 e78 na qual revela a tese central do livro que é a de que a violência na escola não está neutra das violências do ambiente externo. Adiante, apresenta a partir dos anos 1980, tipos de violência que surgiram contra a escola e da escola, uma das saídas enfatizada é a busca da gestão democrática e da construção de novas políticas públicas.

Este capítulo é central para o leitor obter subsídios para compreender a multidimensionalidade do conceito da violência, suas manifestações nos espaços escolares e suas relações com questões externas, como apresenta o capítulo: violência do desemprego, associada ao uso de álcool, cigarro e drogas, da exclusão de alunos do ambiente escolar, da mídia/instituições e seus padrões de inclusão e exclusão, ainda, relacionada a violência intrafamiliar/domiciliar e 
contra a mulher e, enfim, socioeconômica. Todas violências que abarcam violações de direitos humanos.

No quarto capítulo a autora sugere "Ações possíveis", recomenda que haja redes de resistência democráticas e caminhos democráticos coletivos. Uma das possibilidades seria a busca da escola justa que segundo Schilling (2014) em experiências de suas pesquisas e intervenções de 2010 e 2013 a escola justa teria: 1- Igualdade de direitos e deveres; 2- Respeito, reciprocidade; 3Mérito, valorização, qualidade do ensino; 4- Diálogo, participação.

Estes pontos colocam a educação como um direito e a autora conclui que muitas escolas da cidade de São Paulo buscaram este caminho e fazem a diferença em suas regiões.

Este livro torna-se fundamental para profissionais e estudantes das áreas de ciências humanas como psicologia, história, filosofia e sociologia que querem empenharem-se na tarefa de buscar compreensões dos fenômenos das violências nas escolas da sociedade atual, da insegurança e da violência. 